departments as a result of these meetings. Trainees also reported that the meetings increased their awareness of departmental changes and that they were more likely to raise concerns at the meetings than directly to a consultant. Consultants have said, 'I think these meetings are really important', 'they have been extremely useful' and 'they help to link team members.'

These meetings are a useful resource for doctors in training, consultants and for the paediatric department as a whole. Shift patterns limit face-to-face contact between team members so these meetings facilitate important communication within the department. They also provide the opportunity for trainees to guide service improvement. This initiative is highly recommended to other departments.

\section{G113(P) CREATING A MENTORING PROGRAMME FOR PAEDIATRIC TRAINEES IN THE LOCAL DEANERY}

E Hoyle, R Odedun, K Macfarlane, C Thorbinson, T Awogbemi. Paediatrics, Alder Hey Children's Hospital, Liverpool, UK

\subsection{6/archdischild-2018-rcpch.109}

Aims Mentoring is recognised by the $\mathrm{RCPCH}$ as a process which can provide valuable support to Paediatricians throughout their careers and is a process which is being introduced more widely in Paediatric training.

The aim of this Quality Improvement Project was to

- Introduce a Mentoring Programme into our local tertiary Children's Hospital to ensure supportive and pastoral care for Junior Colleagues was available

- To implement a Mentoring Programme Deanery Wide for all trainees to access

Methods A pilot scheme to mentor foundation year doctors/ GP trainees was undertaken in December 2016. All paediatric trainees rotating into the Children's hospital were contacted asking to express interest in mentoring. They were then matched with interested mentees. During induction week, information was provided to both mentors and mentees to explain the programme in further detail. Feedback was collected at two time periods during the 4 month process. A further programme has been rolled-out and we are currently creating a deanery wide scheme for all Paediatric trainees to access.

Results A total of 18 mentoring partnerships were matched in the pilot scheme. Feedback for mentees was 4/18 and for mentors $5 / 15$. This did not improve in the follow-up programme where feedback was $4 / 13$ and $6 / 13$ for mentors and mentees respectively.

The feedback received included both positive and negative comments which have been acted upon to improve and develop the mentoring process.

Conclusion The main barrier we have encountered has been in relation to feedback which has been significantly suboptimal on both programmes. The feedback we have received has provided us with recommendations for improvement which we have attempted to integrate.

Currently, we are creating a wider mentoring programme for all Paediatric trainees to access in the local Deanery. This will be rolled out in March 2018. There will be more active participation from mentees, including having a mentee-driven matching process. There will be a dedicated website for mentoring and we hope to provide local mentoring skills training. Our aim will be to seek permission to include compulsory (but anonymous) provision of feedback as part of the trainee's responsibilities.

\section{G114(P) CHROMOSOME AND URINE CYTOMEGALOVIRUS TESTING IN SYMMETRICALLY GROWTH RETARDED INFANTS}

P Muthusamy, S Davies, E Bouldalaki, P Loganathan. Neonatal Unit, Department of Paediatrics, North Tees and Hartlepool NHS Foundation Trust, Stockton on Tees, UK

\subsection{6/archdischild-2018-rcpch.110}

Aims Chromosome analysis and cytomegalovirus (CMV) infection screening are commonly being done to investigate the underlying cause for symmetrical intra uterine growth restriction (IUGR). However, recent papers express the concern of low yield and associated high cost. Microarray testing has a high rate of incidental findings seen in the general population which may create unnecessary anxiety among the parents. Our objective is to evaluate the significance of chromosomal disorders and urine CMV in symmetrically IUGR babies.

Methodology This was a retrospective cohort study of IUGR babies over a six-year (2011-2017) period in a tertiary neonatal unit. We collected details of IUGR babies by using neonatal database and case notes. Genetic results were obtained from regional genetic database and CMV results from electronic reporting system.

Results Results are shown in the table 1:

\begin{tabular}{llll}
$\begin{array}{l}\text { Abstract G114(P) Table 1 } \\
\text { Referrals/category }\end{array}$ & Total & $\begin{array}{l}\text { Non-IUGR* } \\
(\%)\end{array}$ & $\begin{array}{l}\text { Symmetrical } \\
\text { IUGR (\%) }\end{array}$ \\
\hline Total number of referrals & 1118 & $\begin{array}{l}956 \\
(85.5 \%)\end{array}$ & $162(14.5 \%)$ \\
Abnormal array results & 179 & $\begin{array}{l}160 \\
(16.7 \%)\end{array}$ & $19(11.7 \%)$ \\
Likely unrelated (incidental) & 26 & $13(1.4 \%)$ & $13(8.0 \%)$ \\
$\begin{array}{l}\text { Unclear significance or possible non-IUGR } \\
\text { significant finding }\end{array}$ & 68 & $64(6.7 \%)$ & $4(2.5 \%)$ \\
Likely causal to reason for referral & 85 & $83(8.7 \%)$ & $2(1.2 \%)$ \\
\hline * Includes all the paediatric and neonatal population & &
\end{tabular}

With abnormal array results, the incidences of incidental findings are $8 \%$ for non-IUGR referrals and $68 \%$ for IUGR referrals. For non-IUGR referrals 52\% appear to explain the referral and in IUGR referrals only 10\% appear to explain the referral. The chance of significant results are higher with non-IUGR referrals than IUGR referrals, so the yield for meaningful chromosome testing.

118 babies had urine CMV testing and 1 had positive result. However, this baby was investigated for clinical presentation of congenital CMV- hepatosplenomegaly and petechial rash.

Conclusions We found that the majority of the findings identified in isolated symmetrical IUGR babies are incidental and do not explain the IUGR. Urine CMV testing should be considered in IUGR babies only if there are clinical features suggestive of intra-uterine infection and chromosome testing only if there are associated phenotypic features or positive family history. 